\title{
Correction to: Applications of Simulation-Based Interprofessional Education in Labor and Delivery
}

Colleen A. Lee, Dena Goffman, Peter S. Bernstein, David L. Feldman, and Komal Bajaj

\section{Correction to: Chapter 17 in: J. T. Paige et al. (eds.), Comprehensive Healthcare Simulation: InterProfessional Team Training and Simulation, Comprehensive Healthcare Simulation, https://doi.org/10.1007/978-3-030-28845-7}

The book was inadvertently published with incorrect affiliation of all the authors in Chapter 17. This has now been corrected in Chapter 17 as below:

Colleen A. Lee MS, RN ${ }^{1}$, Dena Goffman MD ${ }^{2,3}$, Peter S. Bernstein MD, $\mathrm{MPH}^{4}$, David L. Feldman MD, MBA ${ }^{5}$, Komal Bajaj MD, MS-HPEd ${ }^{4,6}$

${ }^{1}$ Weill Cornell Medicine

Physician Organization-Quality and Patient Safety

New York, NY, USA

${ }^{2}$ Department of Quality and Patient Safety

New York-Presbyterian Hospital

New York, NY, USA

${ }^{3}$ Department of Obstetrics and Gynecology

Columbia University Medical Center

New York, NY, USA

${ }^{4}$ Department of Obstetrics \& Gynecology and Women's Health

Albert Einstein College of Medicine/Montefiore Medical Center

Bronx, NY, USA

${ }^{5}$ Healthcare Risk Advisors, The Doctors Company

New York, NY, USA

${ }^{6}$ Department of Obstetrics and Gynecology

Jacobi Medical Center, NYC Health + Hospitals

Bronx, NY, USA 